\title{
Analysis Occurrence of Equatorial and Low Latitude Ionospheric Scintillations Over Indonesia
}

\author{
Sri Ekawati \\ Ionosphere and Telecommunication Division, Space Science Application Center, LAPAN \\ Jl. Dr. Djundjunan No. 133 Bandung, West Java, Indonesia 40173, \\ e-mail : ekawa_srie@bdg.lapn.go.id
}

\begin{abstract}
Strong scintillations over Pontianak $\left(0.2^{\circ} \mathrm{N} 109.20^{\circ} \mathrm{E}\right.$, geomagnetic latitude is $\left.6.09^{\circ} \mathrm{N}\right)$, and over Bandung $\left(6.5^{\circ} \mathrm{S} 107.3^{\circ} \mathrm{E}\right.$, geomagnetic latitude is $\left.16.5^{\circ} \mathrm{S}\right)$ was compared to find out the spatial distribution of ionospheric scintillation. Data was obtained from GISTM GSV4004B. Percentage occurrence of strong scintillation was counted at each observation station. Result showed the occurrence of scintillation over Pontianak was higher than Bandung, but on March and on September, the occurrence of scintillation over Bandung higher than in Pontianak. Furthermore, the scintillation occurrence in March-April is higher than in September-October. Other result showed there was anomaly at August 16, 2010 related to solar activity.
\end{abstract}

\section{Introduction}

Ionospheric Scintillation, which causes significant effects on satellite signals for communication and navigation, often takes place in equatorial region [1]. Ionospheric scintillation is a rapid fluctuation of radiofrequency signal phase and/or amplitude, generated as signal passes through the ionosphere $[2,3,4,11]$. LAPAN uses GPS Silicon Valleys's GPS Ionospheric Scintillation and TEC Monitor (GISTM) system Model GSV4004B to monitor Ionospheric Scintillation over Pontianak $\left(0.2^{\circ} \mathrm{N} 109.20^{\circ} \mathrm{E}\right.$, geomagnetic latitude is $\left.6.09^{\circ} \mathrm{N}\right)$ and Bandung $\left(6.5^{\circ} \mathrm{S} 107.3^{\circ} \mathrm{E}\right.$, geomagnetic latitude is $\left.16.5^{\circ} \mathrm{S}\right)$ as shown in Fig 1.

Equatorial scintillation happens when small-scale irregularities in the F region of the ionosphere affect the radio-frequency signals. Influenced by the pressure gradients and gravity, the equatorial plasma present in the F2 layers is forced downward along the magnetic field lines [4]. This process creates a belt of enhanced electron density from $15^{\circ}$ to $20^{\circ}$ on both sides of the geomagnetic equator as illustrated in Fig 2(a) $[4,8,11]$. This particular region where the electron density in enhanced is referred to as the Equatorial Anomaly. The process by which they are created is known as the Fountain Effect. This process is illustrated in Fig.2(b), where the Equatorial Fountain is indicated by the ExB drift, which drives the plasma upward. This plasma is the diffused along B field under the influence of gravity, $\mathrm{g}$, and pressure gradients $\mathrm{p}$. This process happens in the daylight hemisphere [5].

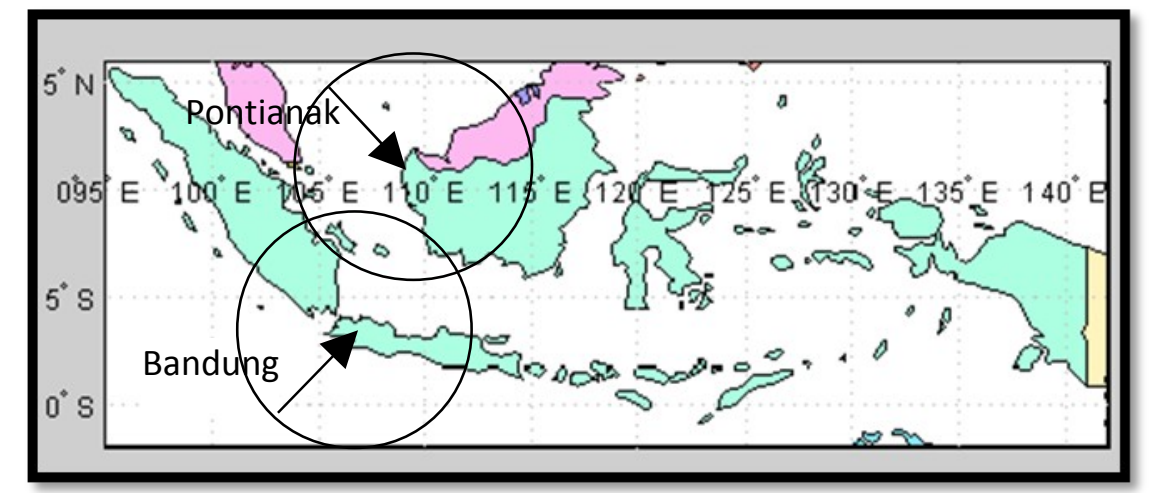

Figure 1. The location of GISTM over Pontianak and Bandung, LAPAN, Indonesia

Base on GISM Chart (Global Ionosphere Scintillation Model), scintillation activity indicated by S4 [12]. Strong scintillation is generally considered to occur when $S_{4}$ is greater than $0.5(0.5<\mathrm{S} 4$ index $\leq 1)$ and is associated with strong scattering of the signal in the ionosphere $[10,12]$. These irregularities scatter radio waves from satellites 
in the frequency range of $100 \mathrm{MHz}-4 \mathrm{GHz}$ [6]. In this present paper we analyzed the occurrence of ionospheric scintillation over Pontianak and Bandung to find out the spatial distribution of strong scintillation between equatorial and low latitude over Indonesia.

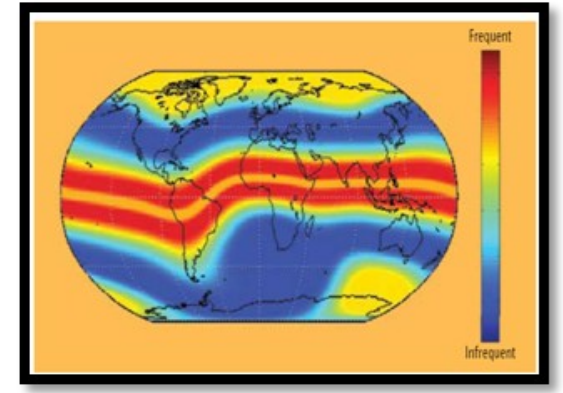

(a)



(b)

Figure 2. (a) Scintillation map showing the frequency of disturbances at solar maximum. Scintillation is most intense and most frequent in two bands surrounding the magnetic equator, up to 100 days per year [9].

(b) Equatorial fountain that gives rise to the equatorial anomaly [4].

\section{Data and Methods}

Data was obtained from GPS Ionospheric Scintillation and TEC Monitor (GISTM) GSV4004B in Pontianak and in Bandung as shown in Fig.1. The amount of data $\mathrm{S}_{4}$-index during the night had calculated its percentage of strong scintillation occurrence. Strong scintillations $(0.5<\mathrm{S} 4$ index $\leq 1)$ over Pontianak and Bandung in 2010 were compared to find out the spatial distribution of ionospheric scintillation. Percentage of strong scintillation occurrence over Pontianak and Bandung on March-April compared with occurrence in September-October. The anomaly of scintillation occurrence during 2010 also been analyzed.

\section{Result and Discussion}

The occurrence rate of scintillations was high on March-April and on September-October [10]. It was clearly shown in Fig. 3 and in Fig. 4, based on data observation over Pontianak and Bandung. Figure 3(a) shows occurrence of strong scintillation over Pontianak from January to December 2010 (DOY 1 to 365). Figure 3 (b) shows comparison between occurrence on March-April (upper panel) and on September-October (bottom panel).

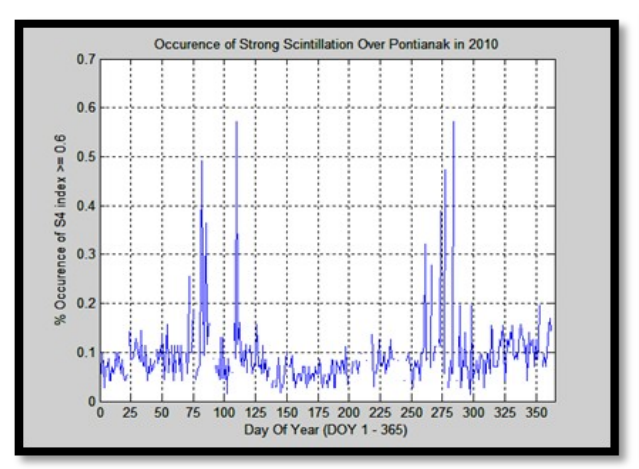

(a)

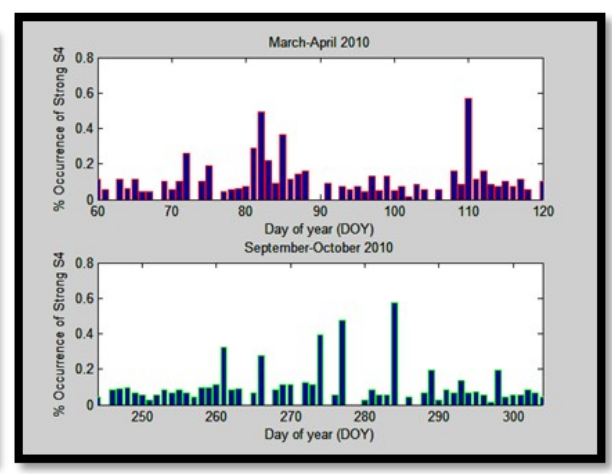

(b)

Figure 3. Occurrence of Strong Scintillation over Pontianak (a) during 2010 (b) comparison between March-April and September-October

If we calculated occurrence of strong scintillation on March-April more than $0.1 \%$, there were 24 days. But, on September-October, there were only 13 days. So, the occurrence over Pontianak on March-April is a little bit 
higher than on September-October. It's mean that there ware asymmetry between scintillation occurrence on MarchApril and September-October.

The asymmetry was very obviously seen in Bandung as shown in Fig.4. Figure 4(a) shows occurrence of strong scintillation over Bandung from January to December 2010. Figure 4(b) shows comparison occurrence of ionospheric scintillation on March-April (upper panel) and on September-October (bottom panel). If we calculated occurrence of strong scintillation more than $0.5 \%$, there were 7 days on March-April and there are only 1 days on September-October.

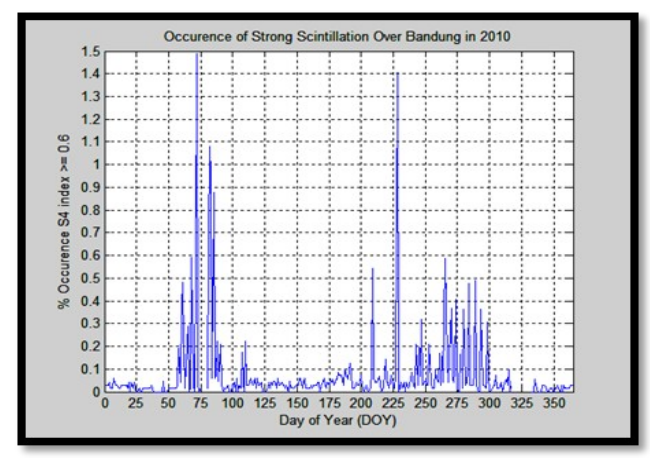

(a)

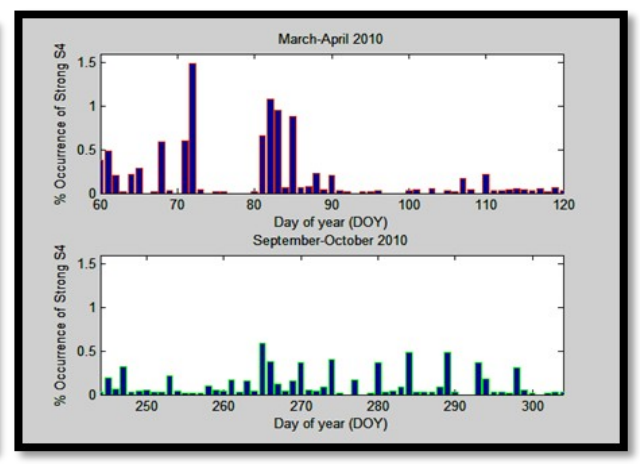

(b)

Figure 4. Occurrence of Strong Scintillation over Bandung (a) during 2010 (b) comparison between March-April and September-October

Figure 5 shows comparison occurrence of strong scintillation between Pontianak and Bandung. Figure 5(a) shows the occurrences in one years (January to December 2010). The Red line is the occurrence over Bandung and the blue one is the occurrence over Pontianak. The interesting thing is the occurrences of strong scintillation over Pontianak are a little bit higher than over Bandung. But, on March, the occurrences in Bandung are rise sharply very higher than in Pontianak. It also occurs on September, the occurrences in Bandung are higher than in Pontianak.

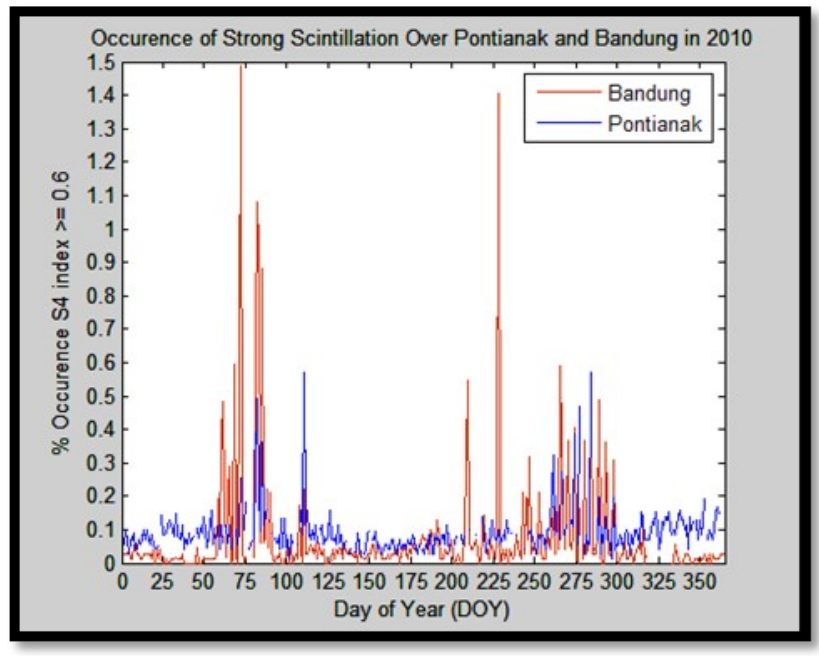

(a)

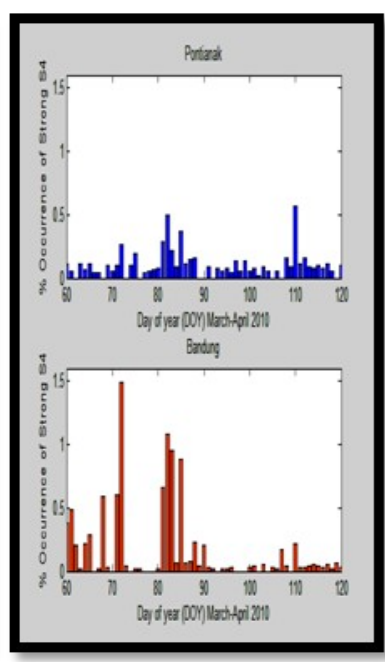

(b)

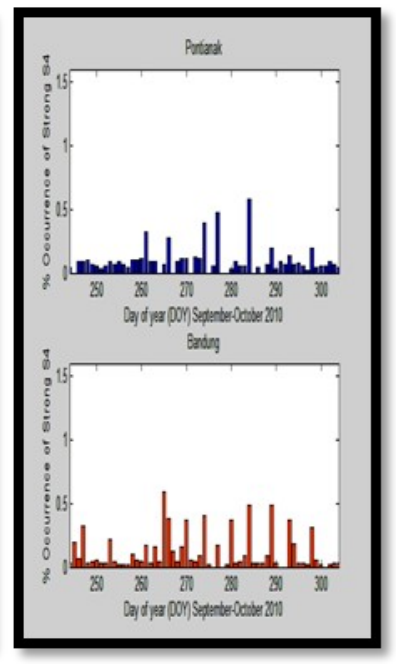

(c)

Figure 5. Comparison occurrences of Strong Scintillation between Pontianak and Bandung (a) during 2010 (b) during March-April (c) during September-October

Figure 5(b) comparison the occurrences on March-April between Pontianak (upper panel) and Bandung (bottom panel). The maximum value over Pontianak was $0.5718 \%$ and the maximum one over Bandung was $1.4875 \%$. If we calculated occurrence of strong scintillation more than $0.5 \%$, there were 7 days over Bandung and there are only 1 days over Pontianak.

Figure 5(c) comparison the occurrences on September-October between Pontianak (upper panel) and Bandung (bottom panel). The maximum value over Pontianak was $0.5737 \%$ and the maximum one over Bandung 
was $0.5882 \%$. If we calculated occurrence of strong scintillation more than $0.3 \%$, there were 4 days over Pontianak and there are 10 days over Bandung.

As mention before that the occurrence rate of scintillation is higher on March-April and September-October. But, in Bandung, there are an anomaly of scintillation occurrence at August 16, 2010 achieved $1.4041 \%$ as shown in Fig. 6. Ionospheric scintillation is related to solar activity. This anomaly also has big probability related to two sunspot solar flare (C4-class) at August 14, 2010.

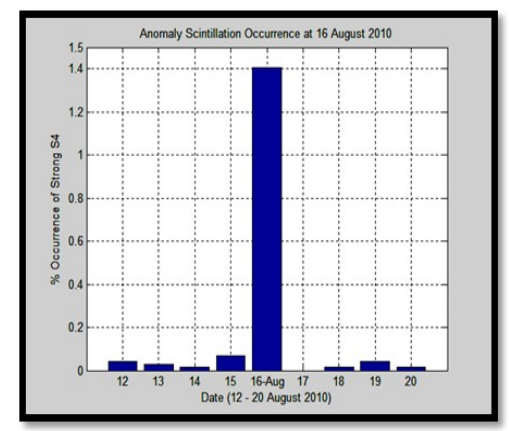

Figure 6. An Anomaly of Scintillation occurrence at August 16, 2010

\section{Conclusion}

The occurrence rate of strong scintillations in both of station (over Pontianak and Bandung) was high on March-April and on September-October. The scintillation occurrence in March-April is higher than in SeptemberOctober. It's mean that there are asymmetry between scintillation occurrence on March-April and SeptemberOctober. The occurrence of scintillation over Pontianak was higher than Bandung, but on March and on September, the occurrence of scintillation over Bandung is higher than in Pontianak. Other result showed there was anomaly of scintillation occurrence at August 16, 2010 related to two sunspot solar flare (C4-class) at August 14, 2010.

\section{Acknowledgment}

Author would like to thank Jiyo as Head of Ionosphere and Telecommunication Division, to S. Supriadi and A. Haryuno for their help providing GISTM data from Bandung, to Space Observatory Division staff for their help providing GISTM data from Pontianak through ftp.

\section{References}

1. Abdullah, M., et al. 2009. "TEC and Scintillation Study of Equatorial Ionosphere: A month Campaign over Sipitang and Parit Raja Stations, Malaysia". American J. Of Engineering and Applied Sciences 2 (1): 44-49, 2009. ISSN 1941-7020.

2. Dubey, S. Et al. 2005. "Effect of Ionospheric Scintillation on GPS Receiver at Equatorial Anomaly Region Bhopal". URSI General Assembly in New Delhi, October 2005.

3. Theerapatpaiboon, P., S. Sukkaewthanom, N. Leelaruji and N. Hemmakorn. 2004. "The Study of Scintillation on C-Band Low Elevation Angle at Sri-Racha Satellite Earth Station.”. ICCAS2004.

4. Moraes,A.O and Perrella, 2009. W.J. "Performance evaluation of GPS receiver under equatorial scintillation". Journal of Aerospace technology and Management. V.1,n.2, Jul. - Dec. 2009.

5. Kelley, M.C, 1989, "The Earth's Ionosphere: Plasma Physics and Electrodynamics", San Diego, Academic Press, 484p.

6. Paul M.Kintner, JR., Todd Humphreys and Joanna Hinks. 2009. GNSS and Ionospheric scintillation : How to Survive the Next Solar Maximum. InsideGNSS : Juli/Agustus 2009. www.insidegnss.com

7. Otsuka Y., Shiokawa K., and Ogawa T. 2006. "Equatorial Ionospheric Scintillations and Zonal Irregularity Drifts Observed with Closely-Spaced GPS Receivers in Indonesia". Journal of the Meteorological Society of Japan, Vol.84A, pp. 343-351.

8. IPS. 2010. Ionospheric Scintillation. http://www.ips.gov.au/Satellite/6/3/1, downloaded September 2010. 